\title{
EFEKTIFITAS PEMBELAJARAN MATEMATIKA MODEL LEARNING CYCLE $5 E$ BERBANTUAN CD INTERAKTIF MATERI SEGITIGA KELAS VII DI SMP N 2 LIMPUNG KABUPATEN BATANG
}

\author{
Lilik Ariyanto \\ IKIP PGRI SEMARANG \\ ariyanto.lilik144@gmail.com \\ Muhammad Prayito \\ IKIP PGRI SEMARANG
}

\begin{abstract}
This study has the objective to determine the effectiveness of mathematic learning with Learning Cycle 5e model using interactive CD of triangle in class VII N 2 Limpung, Batang. This type of research is experimental research. Variables used in this study were: (1) student learning outcomes, obtained with the test, (2) creativity of student learning obtained from observations.

The results of field trials demonstrated experimentally achieve effective classroom learning include, (1) study completed by the $Z=-1.48$ classical individually and with one test sample value sig (2-tailed) is 0.016, (2) creativity affects the outcome learning seen from the $R$ square in Model Summary table obtained $0.660=66 \%$., and (3) there is a difference between a class to learn the results of experimental and control classes with values in the table Independent sig Test Samples of $0.029=2.9 \%$, the average value the average grade of 70.57 experimental and control classes for 60.93 it can be concluded that the experimental class learning better learning outcomes compared to the control class.
\end{abstract}

Keywords: Effectiveness, Learning Cycle 5e, Interactive CD

\begin{abstract}
ABSTRAK. Penelitian ini mempunyai tujuan mengetahui efektivitas pembelajaran matematika model Learning Cycle 5e berbantuan CD interaktif materi segitiga kelas VII di SMP N 2 Limpung kabupaten Batang. Jenis penelitian ini adalah penelitian ekperimen. Variabel yang digunakan dalam penelitian ini adalah: (1) hasil belajar siswa, diperoleh dengan tes; (2) kreativitas belajar siswa yang diperoleh dari hasil observasi.

Hasil uji coba lapangan menunjukkan pembelajaran kelas eksperimen mencapai efektif meliputi, (1) pembelajaran tuntas dengan hasil $Z_{\text {hitung }}=-1,48$ secara individu maupun klaksikal dengan one sample tes nilai sig (2-tailed) adalah 0,016, (2) kreativitas berpengaruh terhadap hasil belajar dilihat dari nilai $R$ square pada tabel Model Summary didapat 0,660 $=66 \%$., dan (3) terjadi perbedaan hasil belajar antara kelas eksperimen dan kelas control dengan nilai sig pada tabel Indipendent Samples Test sebesar 0,029 = 2,9\%, hasil nilai rata-rata kelas eksperimen sebesar 70,57 dan kelas kontrol sebesar 60,93 dapat disimpulkan bahwa hasil belajar kelas eksperimen lebih baik dibandingan hasil belajar kelas kontrol.
\end{abstract}

Kata Kunci : Efektivitas, Learning Cycle 5e, CD Interaktif 


\section{PENDAHULUAN}

\section{A. Latar Belakang}

Setiap pribadi manusia memiliki potensi dan talenta dalam dirinya, tugas pendidikan yang sejati adalah membantu peserta didik untuk menemukan dan mengembangkan seoptimal mungkin. Dalam UU No. 20 Tahun 2003 tentang Sistem Pendidikan Nasional pada Bab II Pasal 3 bahwa: Pendidikan berfungsi mengembangkan kemampuan dan membentuk watak serta peradaban bangsa yang bermartabat dalam rangka mencerdaskan kehidupan bangsa, bertujuan untuk berkembangnya potensi peserta didik agar menjadi manusia yang beriman dan bertaqwa kepada Tuhan Yang Maha Esa, berakhlak mulia, sehat, berilmu, cakap, kreatif, mandiri dan menjadi warga negara yang demokratis serta bertanggung jawab.

Salah satu materi pelajaran matematika yang masih sering menjadi kendala adalah geometri. Sehingga diperlukan sarana untuk memudahkan peserta didik dalam membayangkan benda-benda abstrak. Sesuai dengan Standar Kompetensi matematika (KTSP 2006), yang memiliki kedudukan paling esensial dalam kurikulum SMP/MTs yaitu geometri dengan proporsi materi sekitar $40 \%$ dari seluruh materi pokok matematika di SMP/MTs. Dalam materi geometri kelas VII terdapat konsep yang dapat dibangun melalui konsep-konsep sebelumnya yang telah diterima oleh peserta didik, salah satunya yaitu materi segitiga. Diperlukan kreativitas dari peserta didik untuk dapat melakukan pendekatan secara bervariasi dan memiliki bermacam-macam kemungkinan penyelesaian terhadap suatu persoalan yang berkaitan dengan materi segitiga. Menurut Munandar (Supriadi, 1997: 60) tujuh sikap, kepercayaan, nilai-nilai yang melekat pada orang-orang yang kreatif, yaitu: (1) terbuka terhadap pengalaman baru dan luar biasa, (2) luwes dalam berpikir dan bertindak, (3) bebas dalam mengekspresikan diri, (4) dapat mengapresiasi fantasi, (5) berminat pada kegiatan-kegiatan kreatif, (6) percaya pada gagasan sendiri, dan (7) mandiri.

Dengan kreativitas, peserta didik dapat menunjukkan kinerja atau karya, hasil perbuatan, baik dalam bentuk gagasan maupun barang secara berkualitas dan bermakna. 
Salah satu pembelajaran matematika yang bercirikan pembelajaran konsruktivisme adalah pembelajaran matematika model Learning Cycle. Model Learning Cycle pertama kali diperkenalkan oleh Robert Karplus dalam Science Curriculum Improvement Study/SCIS (Wena, 2009: 170). Dengan model Learning Cycle siswa dapat berperan aktif untuk menggali, menganalisis, mengevaluasi pemahamannya terhadap konsep yang dipelajari. Dengan demikian, kemampuan analisis, evaluatif, dan argumentatif peserta didik dapat berkembang dan meningkat secara signifikan (Hanuscin and Lee, 2008).

Untuk memudahkan proses belajar peserta didik juga membutuhkan media pembelajaran yang merangsang pikiran, perasaan, perhatian dan kemampuan peserta didik ke arah yang lebih baik. Untuk memenuhi hal tersebut kiranya perlu CD ineraktif yang berisi materi audio visual. Menurut Anitah (2009: 59) media interaktif merupakan media yang meminta siswa mempraktikkan suatu keterampilan dan menerima balikan, sedangkan CD merupakan kepingan berbentuk cakram padat. SMP N 2 Limung dilengkapi dengan ruang multimedia dan laboratorium komputer yang mempunyai kriteria cukup baik. Dengan demikian, pemanfaatan $\mathrm{CD}$ interaktif yang optimal diharapkan mampu menjadi solusi agar pembelajaran menjadi lebih bermakna dan pencapaian hasil belajar peserta didik akan lebih efektif.

\section{B. Rumusan Masalah}

Permasalahan dalam penelitian ini adalah: "Apakah penerapan pembelajaran matematika model Learning Cycle 5E berbantuan CD interaktif materi segitiga kelas VII di SMP N 2 Limpung efektif"

\section{Tujuan}

Tujuan yang ingin dicapai melalui penelitian ini adalah untuk mengetahui efektivitas pembelajaran matematika model Learning Cycle 5E berbantuan CD interaktif materi segitiga kelas VII di SMP N 2 Limpung.

\section{Manfaat}

Adapun Adapun manfaat yang diharapkan dari hasil penelitian, sebagai berikut: 
1) Melalui penelitian ini diharapkan dapat memberikan suatu referensi para pendidik tentang pembelajaran/ media yang digunakan untuk meningkatkan hasil belajar mahasiswa.

2) Melalui pembelajaran menggunakan Model Learning Cycle 5e berbantuan CD Interaktif, mahasiswa diharapkan terfasilitasi untuk aktif dalam pembelajaran.

\section{METODE PENELITIAN}

\section{A. Desain Penelitian}

Desain penelitian ini menggunakan jenis penelitian QuasiExperimental, yang dapat dilihat pada gambar 3.1 berikut.

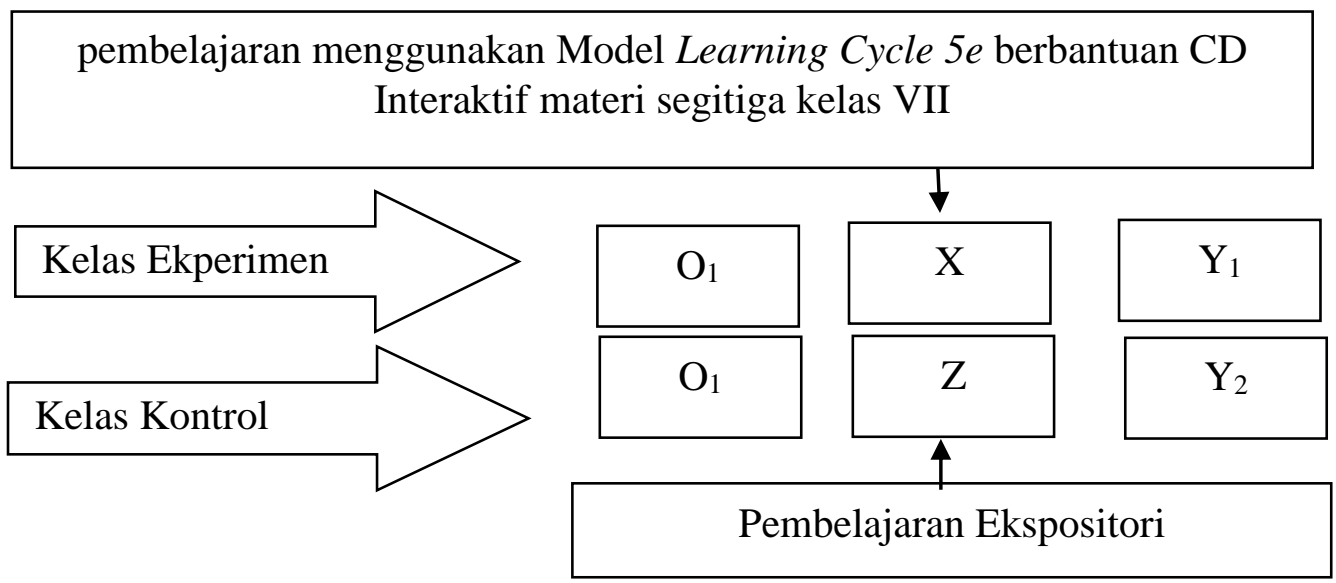

Gambar 1 Desain Quasi Esperimen (Samsudi, 2006: 75)

Keterangan:

O : Nilai Pre Test Matematika.

Y : Keefektivan pembelajaran (Ketuntasan, pengaruh kreativitas terhadap prestasi belajar, dan perbandingan prestasi belajar siswa)

$\mathrm{X}$ : Treatment atau perlakuan dengan pembelajaran matematika menggunakan Model Learning Cycle $5 e$ berbantuan CD Interaktif.

Z : Pembelajaran matematika melalui pembelajaran ekspositori

\section{B. Waktu dan Tempat Pelaksanaan}

Penelitian ini dilaksanakan mulai bulan Desember 2011, untuk pelaksanaan uji coba dilaksanakan pada bulan Februari 2012. Tempat pelaksanaan penelitian SMP Negeri 2 Limpung Kabupaten Batang 


\section{Populasi dan sampel}

Populasi yang diambil pada penelitian adalah siswa kelas VII SMP N 2 Limpung yang berjumlah 161. Dengan cara mengambil nilai matematika dari ujian nasional sehingga diperoleh nilai awal untuk menentukan bahwa sampel penelitian berasal dari kondisi yang sama atau homogen, setelah itu kita dapat memilih secara acak dua kelas sampel yaitu 1 kelas VII sebagai kelas ekperimen yaitu kelas VII B dan 1 kelas VII sebagai kelas Kontrol yaitu kelas VII A. sedangkan kelas yang digunakan untuk uji coba soal yaitu kelas VII F.

\section{Teknik Pengumpulan data}

Teknik pengumpulan data pengembangan yang digunakan dalam penelitian ini adalah sebagai berikut.

(1) Metode Dokumentasi

Metode dokumentasi dalam penelitian ini digunakan untuk memperoleh data-data tertulis tentang daftar nama peserta didik, jumlah peserta didik dan data lain di peserta didik pada materi segitiga kelas VII SMP N 2 Limpung yang akan digunakan untuk kepentingan penelitian

(2) Metode Observasi

Metode ini digunakan untuk mengamati kreativitas peserta didik pada saat pembelajaran.

(3) Metode Tes

Metode tes digunakan untuk mendapatkan nilai hasil belajar peserta didik pada materi segitiga kelas VII SMP N 2 Limpung.

\section{E. Analisis Data}

Data yang telah dikumpulkan melalui instrumen-instrumen kemudian dianalisis. Data yang dianalisis adalah sebagai berikut. 
(1) Analisis Data Tes Hasil Belajar

Pelaksanan tes ini bertujuan untuk mengetahui efektivitas kepekaan butir tes terhadap pembelajaran serta untuk mengetahui kualitas tes dan sebagai masukan untuk merevisi kembali butir soal, maka yang perlu terlebih dahulu diketahui adalah Validitas, Reliabilitas, daya Pembeda, dan Taraf kesukaran.

(2) Uji Hipotesis

Uji hipotesis meliputi Uji homogenitas, uji normalitas, uji ketuntasan belajar, Uji perbedaan dua rata-rata, uji proporsi, dan Regresi.

\section{HASIL PENELITIAN DAN PEMBAHASAN}

\section{A. Hasil dan Pembahasan Hasil Uji Coba Lapangan}

Langkah pertama adalah menguji apakah kelas VII A dan VII B berdistribusi normal dan homogen. Untuk keperluan menguji ini, peneliti menggunakan data hasil ulangan umum mata pelajaran matematika semester I tahun ajaran 2011/2012. Berdasarkan hasil pengujian normalitas dan homogenitas dapat dikatakan bahwa kelas VII A dan kelas VII B adalah kelas yang berdistribusi normal dan homogen. Selanjutnya dipilih kelas VII B sebagai kelas eksperimen dimana proses pembelajaran menggunakan perangkat pembelajaran matematika model learning cycle berbantuan CD interaktif dan kelas VII A sebagai kelas kontrol.

\section{B. Ketuntasan Hasil Belajar}

Ketuntasan hasil belajar diukur dari ketuntasan individual dan ketuntasan klasikal. Uji ketuntasan belajar peserta didik secara individual mencapai lebih dari 80\%. Sedangkan untuk uji ketuntasan klasikal diperoleh nilai rata-rata ketuntasan belajar di kelas eksperimen mencapai lebih dari atau sama dengan 65 .

Keberhasilan ini disebabkan karena penerapan learning cycle $5 e$ dalam pembelajaran menjadikan peserta didik lebih aktif, baik dalam kegiatan percobaan maupun diskusi kelas dan menjadikan peserta didik mudah memahami suatu konsep sehingga hasil belajar peserta didik lebih 
baik .Peserta didik belajar dalam kelompok kecil yang kemampuannya heterogen. Dalam menyelesaikan tugas kelompok, setiap anggota saling bekerjasama, berinteraksi antar peserta didik.. Hal itu sejalan dengan penelitian Renner (Wena, 2009: 176) bahwa penggunaan learning cycle dapat meningkatkan hasil belajar. Berdasarkan hasil ini membuktikan bahwa pembelajaran dengan menggunakan perangkat pembelajaran matematika model learning cycle $5 e$ dapat menuntaskan hasil belajar peserta didik.

\section{Pengaruh Kreativitas terhadap Hasil Belajar}

Berdasarkan uji pengaruh yang dilakukan diperoleh $R$ square sebesar $66,6 \%$ dan persamaan estimasi regresi $\hat{Y}=-1,662+0,992 X_{1}$ Variabel $\mathrm{X}_{1}$ menyatakan kreativitas peserta didik, dan variabel $\hat{Y}$ menyatakan hasil belajar. Hal itu menunjukkan bahwa kreativitas dan kedisiplinan mempengaruhi hasil belajar sebesar 66,6\%.

\section{Perbandingan Hasil Belajar Kelas Eksperimen dengan Kelas Kontrol}

Berdasarkan hasil nilai rata-rata kelas eksperimen sebesar 70,57 dan kelas kontrol sebesar 60,93 dapat disimpulkan bahwa kelas eksperimen mempunyai nilai rata-rata ketuntasan lebih tinggi dibandingan nilai rata-rata ketuntasan kelas kontrol. Hal ini menunjukkan pembelajaran matematika model learning cycle $5 e$ berbantuan $\mathrm{CD}$ interaktif yang diterapkan pada kelas eksperimen telah mampu meningkatkan hasil belajar peserta didik dibandingkan dengan peserta didik pada kelas kontrol.

Dengan demikian perangkat pembelajaran matematika model learning cycle $5 e$ berbantuan $\mathrm{CD}$ interaktif pada materi segitiga, telah memenuhi dua hal yaitu perangkat pembelajaran yang valid dan pembelajaran yang efektif. Pembelajaran efektif dapat dilihat dari (1) pembelajaran memenuhi ketuntasan baik secara individual maupun kaksikal, (2) kreativitas dan kedisiplinan peserta didik berpengaruh positif terhadap hasil belajar, (3) hasil belajar peserta didik menggunakan model 
learning cycle $5 e$ berbantuan $\mathrm{CD}$ interaktif lebih baik daripada hasil belajar peserta didik kelas kontrol.

\section{KESIMPULAN}

Pembelajaran materi segitiga dengan pembelajaran matematika model learning cycle $5 e$ berbantuan $\mathrm{CD}$ interaktif untuk meningkatkan kemampuan konsep materi segitiga kelas VII efektif, hal ini dapat dilihat dari:

a. Hasil belajar pembelajaran matematika model Learning Cycle 5E berbantuan CD interaktif materi segitiga kelas VII SMP N 2 Limpung tuntas dengan hasil $\mathrm{Z}_{\text {hitung }}=-1,48$ secara individu maupun klaksikal dengan one sample tes nilai sig (2-tailed) adalah 0,016.

b. Terjadi perbedaan hasil belajar antara kelas eksperimen dan kelas kontrol dengan nilai sig pada tabel Indipendent Samples Test sebesar 0,029 = 2,9 $\%$, hasil nilai rata-rata kelas eksperimen sebesar 70,57 dan kelas kontrol sebesar 60,93 dapat disimpulkan bahwa Hasil belajar pembelajaran matematika model Learning Cycle 5E berbantuan CD interaktif materi segitiga kelas VII SMP N 2 Limpung lebih baik.

c. Ada pengaruh kreativitas terhadap hasil belajar pembelajaran matematika model Learning Cycle 5E berbantuan CD interaktif materi segitiga kelas VII SMP N 2 Limpung dilihat dari nilai R square pada tabel Model Summary didapat $0,660=66 \%$.

\section{UCAPAN TERIMAKASIH}

Terselesaikannya penulisan laporan penelitian ini tidak terlepas dari bantuan dan dukungan dari berbagai pihak. Oleh karena itu, dalam kesempatan ini penulis ingin memberikan ucapan terima kasih dan penghargaan yang setinggitingginya kepada mereka yang telah membantu penulis dalam menyelesaikan penelitian ini. Ucapan terima kasih dan penghargaan penulis ucapkan kepada yang terhormat:

1. Muhdi, SH., M.Hum,. Rektor IKIP PGRI Semarang.

2. Ir. Suwarno Widodo, M.Si., Kepala LPPM IKIP PGRI semarang. 
3. Yeni Setiyaliawati, S.Pd, Guru Mitra SMP N 2 Limpung

4. Pihak-pihak yang membantu penelitian ini.

Akhirnya semoga bantuan yang telah diberikan kepada penulis, mendapat balasan yang indah dari Tuhan yang maha murah. Penulis menyadari tulisan ini masih banyak kekurangan, oleh karena itu segala saran dan kritik akan selalu penulis harapkan demi perbaikan yang lebih sempurna. Semoga penelitian ini dapat memberikan sumbangan berarti dalam dunia pendidikan. Amin.

\section{DAFTAR PUSTAKA}

Anitah, S. (2009). Media Pembelajaran. Surakarta: FKIP UNS.

Hanuscin, D. L. dan Lee, M. H. (2008). Using the Learning Cycle as a Model for Teaching the Learning Cycle to Preservice Elementary Teachers. Journal of Elementary Science Education. Vol. 20, No. 2 (Spring), pp. 51-56.

Samsudi. (2009). Desain Penelitian Pendidikan. Semarang: Unnes Pres.

Supriadi, D. (1997). Kreativitas, Kebudayaan, dan Perkembangan Iptek. Bandung: CV. Dwi Rama.

Wena, M. (2009). Strategi Pembelajaran Inovatif Kontemporer: Suatu Tinjauan Konseptual Operasional. Jakarta: Bumi Aksara. 